\title{
Sensibilidade da técnica de reação em cadeia da polimerase para HIV-1 em relação à técnica de ensaio imunoenzimático
}

Priscila R. Rezende

Giselle B. Alves ${ }^{1}$

Luciana M.C. Maradei-Pereira ${ }^{1}$

Teonice J.L. Vale

Adriana S.C. Pimenta

José A.R. Lemos
O vírus da imunodeficiência humana (HIV) é o agente etiológico da Sindrome da Imunodeficiência Adquirida, AIDS, uma doença de grande preocupação médica. O genoma deste vírus encontra-se arranjado em nove genes individuais e por duas estruturas idênticas denominadas de repetiçôes terminais nas extremidades 5' e 3'. Tivemos como objetivo analisar a sensibilidade do teste da reação em cadeia da polimerase (PCR) e o teste de ensaio imunoenzimático (ELISA), como teste para triagem de doadores de sangue para HIV. Foram analisadas 200 amostras de doadores e pacientes, da Fundação HEMOPA, com padrão positivo e indeterminado no teste ELISA. Na triagem sorológica pelo ELISA tiveram como resultado 35 amostras positivas, 75 amostras negativas e 90 amostras indeterminadas as quais foram submetidas ao teste pela PCR. Vinte e cinco amostras tiveram resultado positivo e 175 amostras negativas. Com estes resultados concluimos que a reação de PCR apresenta-se positiva somente nas amostras em que o teste ELISA apresenta relação DO/cutoff, acima de 3. Rev.bras.hematol.hemoter.,2002,24(1): 25-28

Palavas-chave: $H I V-1, P C R$, ELISA

\section{Introdução}

O vírus da imunodeficiência humana pertence à família Retroviridae, subfamília Lentivirinae, gênero Lentivirus (1), o qual é o agente etiológico da Síndrome da Imunodeficiência Adquirida, AIDS, uma das doenças de grande preocupação médica e social (2).

A reação em cadeia da polimerase (PCR) tem melhorado significativamente o diagnóstico molecular nos últimos anos, seguindo uma rápida replicação in vitro e a subseqüente identificação de seqüências específicas do ácido nucléico. A amplificação de seqüências de DNA humano e de muitos DNA alvos resulta, freqüentemente, em uma produção abundante e específica do fragmento desejado, permitindo então, a detecção simples e sem ambigüidade do produto de diagnóstico (3).

O princípio da técnica de PCR é simples e baseia-se em ciclos de síntese de DNA, onde cada ciclo é constituído por três passos: 1) desnaturação da dupla fita de DNA,

1 - Divisão de Biologia Molecular, Fundação HEMOPA - Centro de Hemoterapia e Hematologia do Pará, Belém-PA

2 - Divisão de Sorologia, Fundação HEMOPA - Centro de Hemoterapia e Hematologia do Pará, Belém-PA

3 - Departamento de Genética, Centro de Ciências Biológicas, Universidade Federal do Pará

Correspondência para: José Alexandre Rodrigues de Lemos

Fundação HEMOPA - Divisão de Biologia Molecular. Travessa Padre Eutíquio, 2109. 66033-230. Belém. PA

Fone: (91) 242-9100 ramal 244. Fax: (91) 242-5435 • E-mail : lemos@ufpa.br 
2) anelamento dos primers, e 3) extensão dos primers. Um ciclo faz tipicamente $\sim 3-5$ minutos e é repetido $20-40$ vezes. Um tubo da reação de PCR contém uma mistura de tampão, nucleotídeos, primers, enzima (TaqDNA-polimerase) e ácido nucléico do espécime de interesse (4).

Neste trabalho tivemos como objetivo a avaliação da sensibilidade da técnica de PCR em indivíduos soro-positivos ou indeterminados para HIV-1 na triagem sistemática de doadores de sangue na Fundação HEMOPA (Belém-Pará) em relação à técnica de ensaio imunoenzimático (ELISA).

\section{Casuística e Método}

Foram selecionadas 200 amostras de doadores e pacientes da Fundação HEMOPA, com padrão positivo, indeterminado e negativo para HIV-1 e HIV-2, pela triagem da técnica de ELISA para serem submetidas a confirmação pela técnica de PCR.

Foram extraídos os DNAs de 200 amostras com o kit GonomicPrep ${ }^{\text {TM }}$ Amersham Pharmacia $\subset$.

Com a obtenção do DNA da amostra a ter o seu resultado confirmado, foi realizado o exame da reação em cadeia da polimerase, do tipo Nested-PCR. Para a primeira reação 1 preparou-se o mix em um tubo de $0,2 \mathrm{~mL}$, multiplicando a quantidade de amostras mais um, pela quantidade de reagentes. Os reagentes utilizados foram: água bidestilada, tampão, cloreto de magnésio, DNTPs, primer $1 \mathrm{com}$ seqüência 5'-CAA TGT ACA CAT GGA ATT-3', primer 2 com seqüência 5'-ATT ACA GTA GAA AAA TTC CC-3' (GenBank acession number K02007) e 1U de Taq-DNA-polimerase. Distribuiu-se $22 \mu \mathrm{L}$ do mix em cada tubo de $0,2 \mathrm{~mL}$. A cada tubo foram adicionados $3 \mu \mathrm{L}$ da amostra de DNA. As amostras foram levadas ao termociclador com o seguinte programa: 1 ciclo de $94^{\circ} \mathrm{C} 5^{\prime}, 54^{\circ} \mathrm{C} 2^{\prime} ; 35$ ciclos de $72^{\circ} \mathrm{C}$, $94^{\circ} \mathrm{C}, 50^{\circ} \mathrm{C}$ e 1 ciclo de $72^{\circ} \mathrm{C} 10^{\prime}$. Ao término da primeira reação, os tubos foram abertos cuidadosamente para evitar contaminação e adicionados $25 \mu \mathrm{L}$ de mix para a segunda reação, que foi preparada da mesma maneira que a primeira reação, apenas substituiu-se os primers externos pelos internos, sendo o primer interno 1 com seqüência 5'-GCA GTC TAG CAG AAG AAG-3' A e o primer interno $2 \mathrm{com}$ seqüência 5'-TGG GTC CCC TCC TGA GGA T3'(GenBank acession number K02007). Os tubos foram levados ao termociclador e acionou-se novamente o programa de 1 ciclo de $94^{\circ} \mathrm{C} 5^{\prime}, 54^{\circ} \mathrm{C} 2^{\prime} ; 35$ ciclos de $72^{\circ} \mathrm{C}, 94^{\circ} \mathrm{C}$, $54^{\circ} \mathrm{C}$ e 1 ciclo de $72^{\circ} \mathrm{C} 10^{\prime}$.

Ao término da segunda reação, procedeuse à detecção do produto de PCR amplificado através eletroforese em $100 \mathrm{~V}$ por uma hora em gel de agarose a $2 \%$, contendo $30 \mu \mathrm{L}$ de brometo de etídio a 1\%, imerso em tampão TBE 1 X. Adicionou-se em cada poço do gel os $50 \mu \mathrm{L}$ do produto de PCR mais $5 \mu \mathrm{L}$ de azul de bromofenol. Foi detectado um fragmento de $299 \mathrm{pb}$ correspondente a alça C2-V3 do gene env do provírus integrado na posição 70297327 (GenBank K02007) (5).

\section{Resultados}

As 200 amostras doadores de sangue que foram submetidas à triagem sorológica pelo teste ELISA tiveram o seguinte resultado: 35 amostras positivas, 75 amostras negativas e 90 indeterminadas. Todas foram submetidas à reação de PCR, as quais tiveram como resultado 25 amostras positivas e 175 amostras negativas (Tabela 1 ).

Os resultados do teste de ELISA tiveram como critérios a análise dos resultados de dois testes de marcas diferentes: um de lisado viral capaz de diagnosticar amostras contaminadas HIV-1 e HIV-2 mais o grupo O e outro também

Tabela1: Resultados de teste ELISA e PCR

\begin{tabular}{|l|l|l|}
\hline \multirow{2}{*}{ ELISA } & \multicolumn{2}{|c|}{ PCR } \\
\cline { 2 - 3 } POS & POS & NEG \\
\hline INC & 25 & 10 \\
\hline NEG & 0 & 90 \\
\hline
\end{tabular}


de lisado viral capaz de diagnosticar HIV-1 e HIV-2 . Os dois testes basearam seus resultados numa margem de $10 \%$ do cut off, sendo os positivos as amostras que apresentaram densidade ótica igual ou maior que $+10 \%$, os negativos aqueles que apresentaram densidade ótica igual ou menor - $10 \%$ e os indeterminados as amostras que apresentaram densidade ótica entre $+10 \%$ e $-10 \%$ (método utilizado por Gonçales et al) em pesquisa com vírus da hepatite $\mathrm{C}(6)$.

Para que o resultado final (análise dos dois testes) seja dado como positivo é preciso que os dois testes tenham resultado positivo e negativo quando os dois testes são negativos e, conseqüentemente, indeterminado quando um dos testes é positivo e o outro negativo ou DO borderline.

\section{Discussão}

Foi observado que as reações de PCR apresentaram amplificação nas amostras com teste ELISA com relação DO/C entre 3 e 19,9 (3), ou seja, somente foi observada amplificação por PCR em amostras com ELISA a partir de $\mathrm{DO} / \mathrm{C}>3$.

Não foi observada em 10 de 35 com teste ELISA positivo (28\%) e este fato pode ser explicado pela possível mutação na região de onde se ligam os primers. Esta observação permite concluir que a ausência de amplificação na reação de PCR não pode ser usada como teste confirmatório negativo para os casos com teste ELISA positivo ou indeterminado. Por este motivo, a PCR pode ser usada como teste confirmatório somente quando apresentar amplificação, ou seja, positivo, para os testes com resultado tanto positivo como indeterminado para ELISA.

Portanto, é recomendável que sejam usados primers a partir de consultas no GenBank de isolados brasileiros, para corrigir o problema de especificidade dos mesmos, que devem ser específicos para a população brasileira. Além disso, é necessário que seja feito seqüenciamento da região analisada do vírus, a alça V3, para verificar possíveis mutações que possam ter levado à inespecificidade dos primers nestas 10 amostras analisadas.

Observou-se também que das amostras indeterminadas no teste ELISA, por apresentarem resultado negativo em um teste e positivo em outro, 6 amostras apresentaram relação DO/C entre 6,2 e 17,9 em um teste e zero em outro, sendo que todas com resultado negativo para PCR. Esta observação pode ser indicativa de reação cruzada devido à alta sensibilidade. Porém, o vírus pode ter sofrido mutações a ponto de não afetar somente a seqüência de ligação do primer, mas também os epítopos utilizados no teste ELISA. Assim, tendo em vista estes resultados, o seqüenciamento, pelo menos da alça V3, tornase recomendável para melhor compreensão de possível mutação dessa região e o seu papel na biologia do HIV-1.

\section{Polymerase chain reaction sensitivity against enzyme immuno assay test virus HIV -1}

Priscila R. Rezende, Giselle B. Alves, Luciana M.C. Maradei-Pereira, Teonice J.L. Vale, Adriana S.C. Pimenta, José A.R. Lemos

\begin{abstract}
The Human Immunodeficiency Virus (HIV) is the etiological agent of the Acquired Immunodeficiency Syndrome, (AIDS), a disease of great concern in the medical world. The genome of this virus is found arranged in nine genes and by two identical structures named terminal repetitions on the 5' and 3' extremities. As our objective, the sensitivity of the Polymerase Chain Reaction (PCR) and Enzyme-Linked Immunoabsorbent Assay (ELISA) tests were analyzed as an evaluation for blood donors who are infected with HIV. Two hundred samples from donors and patients from the HEMOPA Foundation were analyzed, with the positive and indeterminate standard of the ELISA test. In the ELISA test selection, the results were thirty-five positive samples, seventy-five negative samples
\end{abstract}


and ninety indeterminate samples. These samples were subsequently submitted to the PCR test where twenty-five samples had a positive result and one bundred seventy five had negative results. With these results we conclude that only samples that had a relation between the optical density and the cutoff above three (ELISA) were found positive in the PCR test.

Rev.bras.hematol.hemoter.,2002,24(1): 25-28

Keywords: $H I V-1, P C R, E L I S A$

\section{Referências Bibliográficas}

1. Coffin JM: Structure and Classification of Retrovirus. In: Levy J. The Retroviridae. Plenun Press, New York 1993; 19-45.

2. Wei X, Ghosh SK, Taylor ME, et al: Viral Dynamics in Human Immunodeficiency Virus Type 1 Infection. Nature 1995; 373:117-22.

3. Zazzi M, Romano L, Peruzzi F, Toneatto S, De Milito A, et Al: Optimal Conditions for
Detection of Human Immunodeficiency Virus Type 1 DNA by Polymerase Chain Reaction with Nested Primers. Mol. Cell. Probes 1993; 7: 431-437.

4. Schochetman G, et al: Polymerase Chain Reaction. J. Infec. Dis. 1988; 158: 1154-1157.

5. Covas DT, Bíscaro TA, Kashima S, Duarte G, Machado AA: High Frequency of the GWG (pro Trp) Envelope Variant of $H I V-1$ in Southeast Brazil. J. Acq. Imm. Def. Syndr. Hum. Retrovirol. 1998; 19: 74-79.

6. Gonçales NSL, Costa FF, Vassallo J, Gonçales Jr FL: Diagnosis of Hepatitis C Virus in Brazilian Blood Donors Using a Rverse Transcriptase Nested Polymerase Chain Reaction: Comparison with Enzyme Immunoassay and Recombinant Protein Immunoblot Assay. Rev. Inst. Med. Trop S. Paulo 2000; 42 (5): 263-267.

Recebido: 10/12/01

Aceito: 24/01/02 